\title{
Price Dynamics and Market Volatility: Behavioral Heterogeneity under Switching Trading Strategies on Artificial Financial Market
}

\author{
Yosra Mefteh Rekik ${ }^{1} \&$ Younes Boujelbene ${ }^{2}$ \\ ${ }^{1}$ Department of Financial and Accounting Methods, Tunisia \\ ${ }^{2}$ Department of Applied Economy, Tunisia \\ Correspondence: Yosra Mefteh Rekik, Department of Financial and Accounting Methods, Tunisia. E-mail: \\ meftehyosra@yahoo.fr
}

Received: February 5, 2015

Accepted: March 10, 2015

Online Published: March 23, 2015

doi:10.5430/ijfr.v6n2p33

URL: http://dx.doi.org/10.5430/ijfr.v6n2p33

\begin{abstract}
In recent years, studying stock markets using multi-agent based models has grow into an important research area due to the fact that this line of attack replicates the nature of the financial market where varied traders with a mixture of expectations and diverse points of rationality network with each other through the market. The main aim of this paper is to include selected finding from behavioral finance into agent model hypothesis. In particular we revise the switching of the trading strategies such as the switching between, uninformed agents, informed agents, zero-intelligence and switchers traders. More precisely we focus on the relationship concerning switching and the excess volatility of the stock market prices and to addresses the question of why traders switch from one type to another.
\end{abstract}

Keywords: heterogeneity, artificial stock market, switching behavior, price dynamics, market volatility

\section{Introduction}

A traditional model in finance is based on a representative, rational investor who makes correct beliefs and has rational expectations about prospect investments. In a standard approach, information is transmitted immediately; asset prices replicate fundamentals and asset allocations are efficient. In the traditional view, traders only interact through the price system. There are two main, contradictory views regarding market mechanisms. On the one hand, theoretical studies idealistically describe market dynamics. They suggest that markets are efficient and assume rational, homogeneous behavior of traders. As the Efficient Market Hypothesis states, efficient markets are markets in which all available information is instantly reflected in the prices, and thus, it is not possible for anyone to consistently outperform the market, other than by chance. Further, rational traders are defined as traders who take the optimal trading decision based on all the information them posses.

In advance, Keynes worried that prices of speculative assets is not only motivated by market fundamentals, but that "market psychology" also plays a vital role. Tversky and Kahneman (1974) suggest that decision behavior under uncertainty is often better explained by simple heuristics and behavioral biases. Furthermore, financial markets has become challenged through developments in noise traders (Sargent, 1993), psychology and behavioral finance (Barberis and Thaler 2003) and agent model hypothesis (Tesfatsion et al. 2006). Recently, the agent model hypothesis to financial analysis has become a promising study field for understanding the complex systems that are practical in financial phenomena.

The agent model simulation is sometimes referred to agent-based computational finance which obviously includes agent-based artificial market (Arthur, 2006). Agent-based modeling offers many more parameters that can be altered to generate different scenarios. It also facilitates the study of emergent properties of traders' interactions and particular classes of traders in isolation. A key challenge for agent-based models is to demonstrate that the resulting price dynamics are indeed consistent with known empirical facts that remain difficult for more standard approaches in many disciplines (Farmer, 2002; Cont, 2007; Lux, 2009). The prices of stocks in financial markets rise and fall over time which then produces the stylized facts. These statistical proprieties are in fact of great attention for making inferences and predictions. By means of modern technologies, one can now find a vast amount of empirical data that record every transaction in stock markets which was not explain by traditional models (Cont, 2001; Chakraborti et al., 
2009).

Our article inquires about the growing literature on agent model hypothesis which elucidate the market dynamics by highlighting the trading strategy of their investors. Important contributions in this area comprise Kirman (1993), Chiarella (1992), Brock and Hommes (1998), LeBaron et al. (1999), De Grauwe et al. (1993), Farmer and Joshi (2002), Lux (1995. According to this study, interactions among heterogeneous and speculators, relying on fundamental trading rules, can produce complex endogenous price dynamics, as well as the appearance of crashes and bubbles. More current approaches are investigated in LeBaron (2006), Hommes (2006), Chiarella et al. (2009), Westerhoff (2009), Lux (2009), and Jiri et al. (2013). In Table below an overview is given on how various approaches handle the hardly observable aspects, and what they conclude about the efficiency of markets.

Table 1. Comparison approaches of market dynamics

\begin{tabular}{|c|c|c|c|}
\hline Approch & Price formation & Trader's behavior & Market efficiency \\
\hline $\begin{array}{l}\text { Theoretical } \\
\text { (Analytical) }\end{array}$ & Simple, linear at equilibrium & Assumed to be rational & Yes \\
\hline Empirical & $\begin{array}{l}\text { No special attention paid } \\
\text { Analyse statistical properties of } \\
\text { real historical data }\end{array}$ & No special attention paid & Anomalies found \\
\hline $\begin{array}{l}\text { Experimental } \\
\text { (Behavioral finance) }\end{array}$ & $\begin{array}{llll}\begin{array}{l}\text { Assume } \\
\text { markets }\end{array} & \text { simple models real }\end{array}$ & $\begin{array}{l}\text { Observe traders' behavior } \\
\text { in action and conclude that } \\
\text { they are "boundedly } \\
\text { rational" }\end{array}$ & Anomalies found \\
\hline Market microstructure & $\begin{array}{l}\text { Analyse price formation in } \\
\text { function of specific trading } \\
\text { mechanisms } \\
\begin{array}{l}\text { Complex } \\
\text { equilibrium }\end{array} \\
\text { nonlinear at at }\end{array}$ & $\begin{array}{l}\text { Investor with asymmetric } \\
\text { information or inventory } \\
\text { management, and learning } \\
\text { market makers }\end{array}$ & $\begin{array}{l}\text { Grade of efficiency is } \\
\text { analysed with respect well } \\
\text { defined fundamental } \\
\text { values } \\
\text { Stylized facts generated }\end{array}$ \\
\hline $\begin{array}{l}\text { Microscopic and agent } \\
\text { based simulation }\end{array}$ & $\begin{array}{ll}\text { Varying: emerges } & \text { from } \\
\text { interaction of individuals } & \end{array}$ & $\begin{array}{l}\text { Boundedly rational, } \\
\text { heterogeneous individuals }\end{array}$ & $\begin{array}{l}\text { Depends on setting and } \\
\text { heterogeneity }\end{array}$ \\
\hline
\end{tabular}

This study is largely motivated by the the modelling approach closely related to the recent development of heterogeneous agent models approach. This research area views the financial market as a complex adaptive system. It uses a bottom-up modelling approach to incorporate the interaction of adaptively heterogeneous behaviour of traders and to examine the complex market behaviour in aggregation.

The rest of the article is structured as follows. Section 2 details our contributions to the literature. Section 3 presents a synthesis on market organizations and the behavior of market participants. Section 4 we evaluate our research objective, and analyze to what degree we managed to answer the research questions. We finish the paper with suggestions for future research.

\section{Contributions to Literature}

This part highlights our most important contributions to the literature by studying past researchers. First, we studies stock markets dynamics using multi-agent based models. The heterogeneous agents' models developed over the last two decades addresses the heterogeneity in decision behavior. It has confirmed that both stochastic (Chiarella et al., 2003, Gallegati et al., 2011) and deterministic (Huang et al., 2010). Heterogeneous agents' models are capable to capture the extreme movement in the asset price through their interaction and specification of diverse types of traders. Huang et al., (2012) and Manahov et al., (2013) prove that this hypothesis can do an improved job of modeling the price dynamics than rational expectations and efficient markets models. In particular, a model is able of duplicating the majority of the stylized facts such as asymmetric return, excessive volatility and volatility clustering, both statistically and quantitatively.

Second, we empirically recognize the diverse set of traders, which are buy side and sell side order, who really switch strategies. Prior studies on agent-based computational models show that investors switch their strategies and their beliefs are key in explanation of some empirical features in financial markets. Following the standard heterogeneous agents' model, we judge a market with a risky asset and different types of traders, fundamentalists, chartists and 
noise traders who are diversified by their information and behaviors about the asset value as well as their trading strategies, jointly with a market maker who adjusts the market price in reaction to the aggregate excess demand of traders behaviors.

Third, this article empirically validates the really switch strategies, which is a significant contribution of some agent-based models for comprehension empirical features in stock markets. Many researchers give confirmation being consistent with strategy switching and show that professionals rely on regressive expectation formation and extrapolative expectation formation (Frankel and Froot, 1990), Westerhoff and Reitz, 2003), and Gilli and Winker, 2003). This becomes explicit in Jongen et al. (2012), who reveal that fundamentalists and chartists modify forecasting behavior over time. Lux (2000) describes stock market with a fixed quantity of trading based on fundamental value and trading based on a mixture of imitative and trend following strategy. The author investigates a possible clarification for volatility clustering in multi-agent literature using a switch in strategies preference.

Fourth, we empirically analyze the behavior participants and we demonstrate that numerous parameters related to switching can affect dynamics prices of the financial markets. We also validate the relationship between market volatility and switching, and much attention has been paid to the question that whether asset prices exhibit excess volatility in empirical studies. Many researchers explain the strategic interactions and volatility (Kirman, 1991, Lux and Marchesi, 1999, 2000, and Gaunersdorfer et al., 2008). In addition, Farmer and Joshi (2002) and Chiarella et al. (2009) show that trend subsequent strategies amplify noise and cause stylized facts in stock markets, such as clustered volatility.

\section{Price Formation and Behavioral Aspects}

\subsection{Asset Pricing}

In our artificial financial market, the agents' portfolio may contain a single financial asset in a continuous double auction market. More specifically, our market is similar to the market presented in Wei et al. (2013). The fundamental value $V_{t}$ occur according to a Poisson process $N(t)$ with parameter $\varphi$ and initial fundamental value $V_{0}$.

$$
\mathrm{v}_{\mathrm{t}+1}=\mathrm{v}_{\mathrm{t}}+\sum^{\mathrm{N}(\mathrm{t})} \delta
$$

Market price $p_{t}$ in time period $t$ is clear as the average of all the transaction prices during the time period. If there is no transaction in the current time period $t$, we take the price of the last period as market prece $\mathrm{P}_{t}=\mathrm{P}_{\mathrm{t}-1}$. The initial market price is equal to the initial fundamental value $\mathrm{P}_{0}=\mathrm{V}_{0}$. The market price is formulated as follow:

$$
p_{t}=\frac{\sum_{n} p_{n}^{t} \times K}{\sum_{n} K}
$$

Where

$\mathrm{K}$ means the order size for each executed $\operatorname{order} \mathrm{P}_{\mathrm{n}}^{\mathrm{t}}$ at time $\mathrm{t}$.

\subsection{Investment Strategy}

Investment strategies are differentiated based on the information that traders exploit to place orders. Investors are classified accordingly as fundamentalist or informed traders, which might be perfectly informed, Uninformed, Noise traders and Switchers. To speed up the simulations, we assume that there are $\mathrm{N}=100$ traders, following Wei et al. (2013). Among which, there are $\mathrm{N}_{\mathrm{I}}=14$ informed traders, $\mathrm{N}_{\mathrm{U}}=30$ uninformed traders, and $\mathrm{N}_{\mathrm{ZI}}=56 \mathrm{ZI}$ traders in our agent-based computational model.

Table 2. Percentage of traders

\begin{tabular}{ccccc}
\hline & Informed & Uninformed & ZIT & Switchers \\
\hline Experience 1 & $14 \%$ & $30 \%$ & $56 \%$ & $0 \%$ \\
\hline Experience 2 & $14 \%$ & $23 \%$ & $56 \%$ & $7 \%$ \\
\hline Experience 3 & $14 \%$ & $15 \%$ & $56 \%$ & $15 \%$ \\
\hline Experience 4 & $14 \%$ & $8 \%$ & $56 \%$ & $22 \%$ \\
\hline Experience 5 & $14 \%$ & $0 \%$ & $56 \%$ & $30 \%$ \\
\hline
\end{tabular}


Similar to Goettler et al. (2009), we will fix 5 different proportions evenly from $0 \%$ to $30 \%$ as switchers' percentages, and thus we consider five different model configurations as illustrated in Table above. The idea is now to judge against the volatility of the market price under different compositions of traders. We normalize the mean arriving time of trader $\lambda=1$. If one time period corresponds to one minute, this implies that, on average, each trader enters the market once in every minute. We set the tick size $\delta=0.01$ and the transaction cost $\mu=0.04$, which is four ticks. Let the initial fundamental value $\mathrm{V}_{0}=20$. Then the variation of the fundamental value is 0.4 per 10 minutes on average. In this paper, however, we keep the time lag the same for all uninformed traders but vary $\tau$ in different scenarios from 60 up to 1200 time periods to examine the effect of the information lag $\tau$. With the set of parameters, we run 30 simulations for statistical significance. For each simulations seed, we run the market under diverse assembly of agents.

\section{Informed agents}

The informed traders in our model symbolize fundamentalist agents in a real market. This type of trader are assumed to have information of the fundamental value $\mathrm{V}_{\mathrm{t}}$, and believe that the expected fundamental value in time period $\mathrm{t}$ is agreed by $\mathrm{P}_{\mathrm{I}, \mathrm{e}}^{\mathrm{e}}=\mathrm{V}_{\mathrm{t}}$.

\section{Uninformed agents}

The uninformed traders know the fundamental value with a time lag, and they use Artificial Neural Networks to predict the market price. We follow Chiarella, Iori and Perello (2009) and assume that the expected fundamental value in the time period $t$ for the uninformed trader $i$, is given by:

$$
\mathrm{p}_{\mathrm{U}, \mathrm{t}}^{\mathrm{e}}=\mathrm{E}_{\mathrm{t}^{\prime}}^{\mathrm{i}}=\frac{1}{\alpha_{\mathrm{t}}^{\mathrm{i}}+\beta_{\mathrm{t}}^{\mathrm{i}}+\gamma_{\mathrm{t}}^{\mathrm{i}}}\left(\alpha_{\mathrm{t}}^{\mathrm{i}} \mathrm{v}_{\mathrm{t}-\tau}+\beta_{\mathrm{t}}^{\mathrm{i}} \overline{\mathrm{p}}_{\mathrm{t}, \tau}+\gamma_{\mathrm{t}}^{\mathrm{i}} \mathrm{p}_{\mathrm{t}}^{\mathrm{m}}\right)
$$

Where the average market price $\overline{\mathrm{p}}_{\mathrm{t}, \tau}$ over the last $\tau$ periods and the mid-price $p_{t}^{m}$ of the current bid $b_{\mathrm{t}}$ and ask $\mathrm{a}_{\mathrm{t}}$ prices, that is:

$$
\begin{aligned}
\overline{\mathrm{p}}_{\mathrm{t}, \tau} & =\frac{1}{\tau}\left[p_{t-1}+p_{t-2}+\ldots+p_{t-\tau}\right] \\
p_{t}^{m} & =\frac{1}{2}\left(a_{t}+b_{t}\right)
\end{aligned}
$$

With:

$\alpha_{\mathrm{t}}^{\mathrm{i}}, \beta_{\mathrm{t}}^{\mathrm{i}}$ and $\gamma_{\mathrm{t}}^{\mathrm{i}}$ are forecasting parameters of the uninformed trader. For the Artificial Neural Networks traders, they optimize these parameters by using a feed-forward neural networks and it is also very efficiently implemented in the software used for this study, Nero-One.

The details of the Artificial Neural Networks learning is given in Wei, Zhang, He and Zhang (2013) who show that the model developed in this paper is able to generate a number of important stylized facts, including leptokurtosis, volatility clustering, ARCH effect and fat tails.

Zero-intelligence traders

Zero-intelligence agents are like in spirit to the "noise traders" of the financial literature. In our market, the ZI agents symbolize some blind market participants. Their forecast for the risky asset's price is a comprehension of a random variable, which they utilize Equation of uniformed traders to predict asset price but the coefficients are random.

$\underline{\text { Switchers }}$

The switchers a priori act as uninformed traders but can switch to an informed traders if they evaluate the cost to do so is low enough (Yamamoto et al., 2013 and Chiarella et al., 2012). The switchers can modify their beliefs and act either as informed or uninformed traders. Since the information of knowing the fundamental value $\mathrm{v}_{\mathrm{t}}$ is valuable they choose if or not to procure that information. They do so by comparing the error made in the last time step predicting the market price $\mathrm{P}_{\mathrm{t}-1}$ using $\mathrm{V}_{\mathrm{t}-1}$, to the error made predicting $\mathrm{P}_{\mathrm{t}-1}$ using $\mathrm{P}_{\mathrm{Ut}, 1}^{\mathrm{e}}$. If the information cost plus the error forecasting $\mathrm{P}_{\mathrm{t}-1}$ using $\mathrm{V}_{\mathrm{t}-1}$ is larger than the error forecasting $\mathrm{P}_{\mathrm{t}-1}$ using $\mathrm{P}_{\mathrm{Ut}, 1}^{\mathrm{e}}$, the trader will stick to his forecast using 
$\mathrm{P}_{\mathrm{Ut}}^{\mathrm{e}}$. If not, the agent will buy the information and use $\mathrm{V}_{\mathrm{t}}$ to forecast. To recapitulate:

$$
p_{S, t}^{e}= \begin{cases}\left(a^{i} \cdot v_{t-\tau}+b^{i} \cdot p_{t}^{a v e}+c^{i} \cdot p_{m}\right)\left(a^{i}+b^{i}+c^{i}\right) & \text { if }\left|p_{U, t-1}^{e}-p_{t-1}\right|<\left|v_{t-1}-p_{t-1}\right|+C \\ v_{t} & \text { if }\left|p_{U, t-1}^{e}-p_{t-1}\right| \geq\left|v_{t-1}-p_{t-1}\right|+C\end{cases}
$$

$\mathrm{C}$ is the information cost. If the agent didn't buy information at time $t-1$, which means he don't know $\mathrm{V}_{\mathrm{t}-1}$ at time $\mathrm{t}$, then he simply treats $\mathrm{P}_{\mathrm{t}-1}$ as $\mathrm{V}_{\mathrm{t}-1}$, so that he can also use Equation above to make his switching decision.

\subsection{The Order Execution Mechanism}

In a dynamic equilibrium model of an order driven market with asymmetric information, Rosu (2010) shows that informed agents submit both market orders and limit orders, depending on whether their informative advantage is about a cutoff. We introduce similar order submission rules as in Rosu (2010) and Wei et al. (2013) where agents who submit limit orders need liquidity compensation, which is at least able to cover the transaction, cost $\mu$. In other terms, buy limit order price can be obtained by subtracting $\mu$ from $\mathrm{P}_{\mathrm{t}}^{\mathrm{e}}$; sell limit order price can be obtained by adding $\mu$ on pet. The order submission rules are accorded to the following scenarios:

Scenario 1: There is at least one ask price and one bid price in the limited order book

$$
\begin{aligned}
& -\mathrm{P}_{\mathrm{t}}^{\mathrm{e}}<\text { ask }+\mu \\
& -\operatorname{ask}+\mu \geq \mathrm{p}_{\mathrm{t}}^{\mathrm{e}} \geq \text { bid }-\mu \& \mid \text { ask }-\mathrm{p}_{\mathrm{t}}^{\mathrm{e}}|\leq| \mathrm{p}_{\mathrm{t}}^{\mathrm{e}}-\text { bid } \mid: \text { Limit order to buy with } \mathrm{p}_{\mathrm{t}}=\mathrm{p}_{\mathrm{t}}^{\mathrm{e}}-\mu \\
& -\operatorname{ask}+\mu \geq \mathrm{p}_{\mathrm{t}}^{\mathrm{e}} \geq \text { bid }-\mu \& \mid \text { ask }-\mathrm{p}_{\mathrm{t}}^{\mathrm{e}}|>| \mathrm{p}_{\mathrm{t}}^{\mathrm{e}}-\text { bid } \mid: \text { Limit order to buy with } \mathrm{p}_{\mathrm{t}}=\mathrm{p}_{\mathrm{t}}^{\mathrm{e}}+\mu \\
& -\mathrm{P}_{\mathrm{t}}^{\mathrm{e}}<\text { bid- } \mu \quad: \text { Market order to sell }
\end{aligned}
$$

Scenario 2: There are no bid prices

$$
\begin{array}{ll}
-\mathrm{p}_{\mathrm{t}}^{\mathrm{e}}>\operatorname{ask}+\mu & : \text { Market order to buy } \\
-\mathrm{p}_{\mathrm{t}}^{\mathrm{e}} \leq \operatorname{ask}+\mu & : \text { Limit order to buy with } \mathrm{p}_{\mathrm{t}}=\mathrm{p}_{\mathrm{t}}^{\mathrm{e}}-\mu
\end{array}
$$

Scenario 3: There are no ask prices

$$
\begin{array}{ll}
-\mathrm{P}_{\mathrm{t}}^{\mathrm{e}}<\text { bid- } \mu & : \text { Market order to sell } \\
-\mathrm{p}_{\mathrm{t}}^{\mathrm{e}} \geq \text { bid }-\mu & : \text { Limit order to sell with } \mathrm{p}_{\mathrm{t}}=\mathrm{p}_{\mathrm{t}}^{\mathrm{e}}+\mu
\end{array}
$$

Scenario 4: There are no ask or bid prices

- With probability $1 / 2$

: Limit order to buy with

- With probability $1 / 2$

\subsection{Strategy Switching}

It has been demonstrated that some parameters related to switching can influence the price dynamics of the market (Brock and Hommes, (2006). Nevertheless, whether switching can intensify or diminish the volatility is still unknown. To do this, we ask: does the switching between diverse agents behaviors aggravate or decrease the volatility of market, or exhibit special character under different situations of market? We consider in our study, the volatility of the market with different structures of traders and we consider how, for a given fixed percentage $\rho$ of switchers, does volatility depend on percentage $\gamma$ of switchers actively buying information at a given instant of time? Our universal conclusions show that superior the percentage $\gamma$ of switchers paying for information at a given time, the lower will be the volatility. This is because the switchers promote the transmission of information and stabilize the market. 


$$
h= \begin{cases}p_{t}-v_{t} & \text { for sell limit order } \\ v_{t}-p_{t} & \text { for buy limit order } \\ p_{t}-v_{t} & \text { for sell market order } \\ v_{t}-p_{t} & \text { for buy market order }\end{cases}
$$

We run the artificial market for 200 times to propose the distinction as a distribution of $\mathrm{C}$. The simulation outcome of distribution for $\mathrm{C}$ is shown in Figure 1.

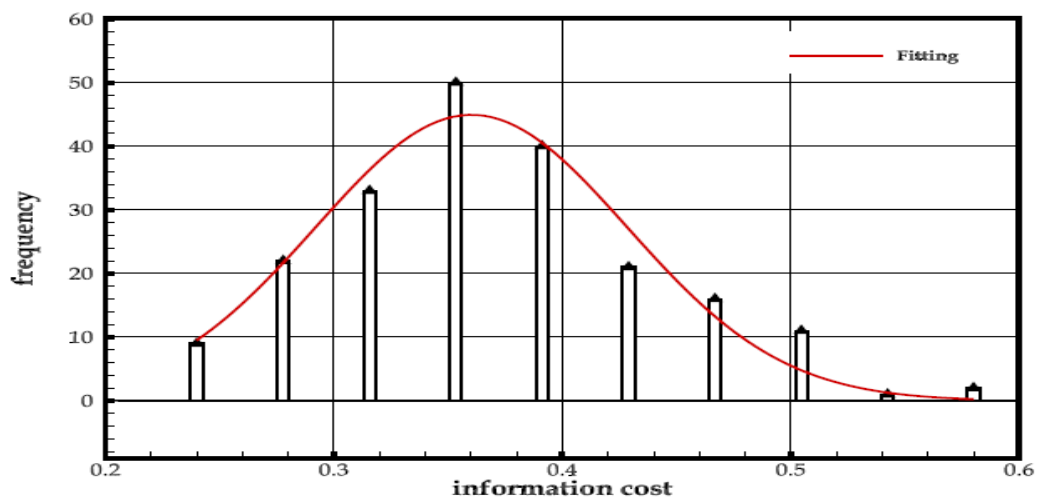

Figure 1. Distribution of information cost $C$ without switchers

The information cost data obey the rules to the normal distribution with function $\mathrm{f}(\mathrm{x})=\mathrm{a} \cdot \exp (-(\mathrm{x}-\mathrm{b} / \mathrm{c}) 2)$. $\mathrm{a}=$ $44.83, \mathrm{~b}=0.3604, \mathrm{c}=0.09662$, and the adjust R2 is 0.9362 . R2 is about 0.95 and the adjusted R2 is 0.9362 , so we can finish off the distribution is really a normal distribution. The average information cost is 0.36 and has a particularly little probability to be negative, which is consistent with the examination exceeding. The estimated information cost will be worn for subsequent simulations.

\section{Results and Interpretations}

\subsection{Stylized Facts}

In recent years, an important challenge of the financial approach is to construct more sophisticated models which have consistencies with as many financial proprieties that cannot be explained by traditional theory. We have constructed the artificial market to see how that emerges the analogous stylized facts with the real one. However, whether the model gives a reliable description of real market data should first be validated. We test the model for the following four factors: autocorrelation, fat tails, volatility clustering and ARCH effect.

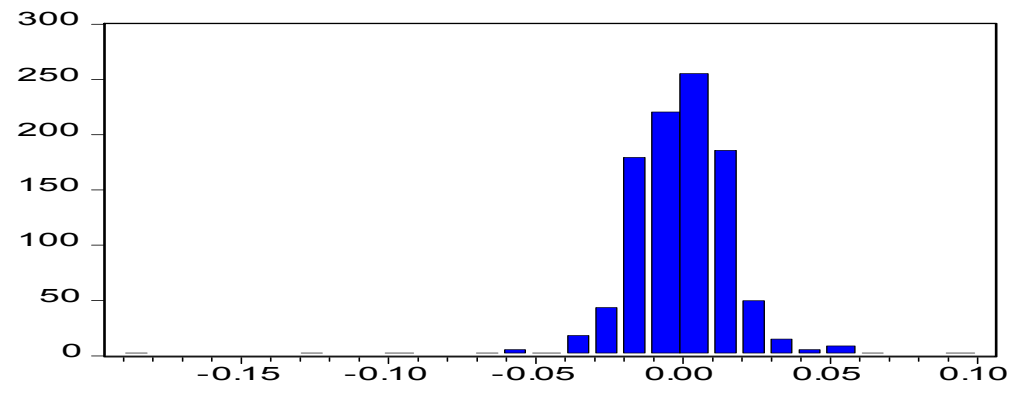

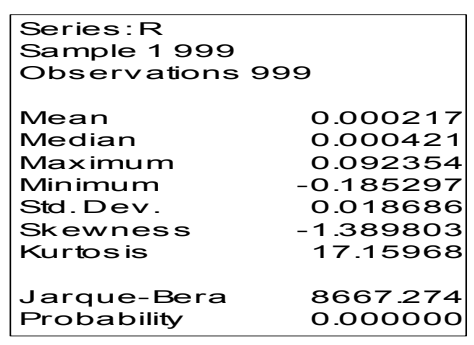

Figure 2. Histogram of simulation results

In Figure 2, we show some statistical characteristics of the market price returns, which allows considering quite clearly the fat-tailed character of the returns. The values of the Jarque-Bera statistics confirm that the distribution of asset returns is significantly different from the normal distribution. The normal asymmetry coefficient or Skewness is generally different from zero and negative $(-1.389803)$ indicating that the asymmetry of the distribution series is 
different from that of the normal distribution. The coefficient of kurtosis is very high, well above 3 (17.15963). This confirms the "fats tails" observed in our artificial market.

A quantile per quantile comparison of the empirical distribution with a theoretical normal can detect differences between two distributions. This is another technique rather than the measurement of the skewness and kurtosis, in order to highlight more significantly the presence of fat tails. In our case, this is an analysis of quantiles, plotting empirical quantiles against the quantiles of the normal distribution. If distributions are identical, the plot should be approximately linear. However, if they are different, we should observe the deviations.

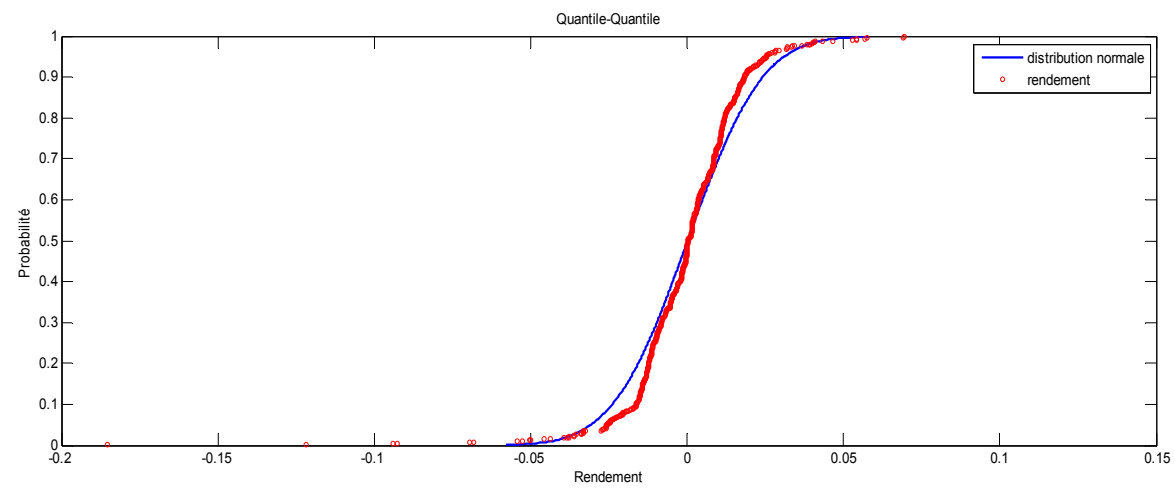

Figure 3. Q-Q Plot

Figure 3 shows that the route of returns quickly ceases to be linear and exhibits strong deviations for both positive and negative tails. The price returns presents larger tails than those of the normal distribution.

Table 3. ARCH test for market price

\begin{tabular}{lccc}
\hline & \multicolumn{3}{c}{ ARCH Test } \\
\hline F-statistic & 474.0514 & p-Value & $0.00^{*}$ \\
Obs* R-squared & 772.8457 & p-Value & $0.00^{*}$ \\
\hline
\end{tabular}

Table 3 indicates that there are ARCH effects of the market price returns. The pattern that we want to explore is the fact of volatility clustering in which large changes tend to follow large changes, and small changes tend to follow small changes (Engle, 1982). The volatility clustering is one of the important stylized facts of finance time series data.

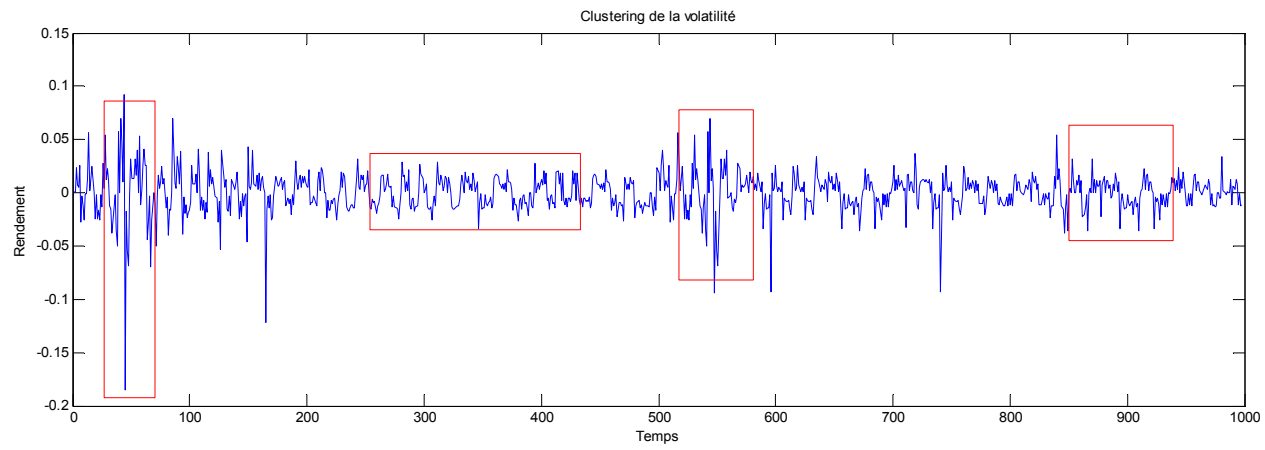

Figure 4. The simulated data of volatility clustering

The volatility clustering illustrated in Figure 4, shows a representation of successive interference with returns which, although not correlated, are dependent. In other words, if return of an action is strong, there is a good chance that the following one has the same fluctuation. The same applies for small volatilities and thus can reproduce the 
phenomenon of volatility clustering.

In our case, the cause of this property is certainly the interaction between the heterogeneous agents: the rational, the chartists, and the noise investors' behavior in financial markets. In fact, as noted above, the proposed model is able to reproduce the stylized facts observed in the real stock market. Concerning the distribution of returns, the model reproduces the "fat tail" and excess kurtosis characterizing the empirical distributions. In other words, this model generates a dynamic pricing with alternating periods of high and low turbulence to reproduce the phenomenon of volatility clustering. An ARCH effect exists on the simulated price returns that are close to the ARCH effects in real returns. These stylized facts are influenced by the nature of the agents' behavior, which reinforces the preliminary results obtained by Anufriev and Panchenko (2013). These findings corroborate similar results of prior research conducted by other authors on global markets (Cont, 2001; LeBaron, 1999; Lux, 2009; Harrison et al., 2010, etc).

\subsection{Simulations Results}

According to the modeling and multi-agent simulation of our model, the combination of several types of agents with different proportions caused a small gap in their basic assets prices. Exacting, we study the effects of variation of agents on price dynamics.

Figure 5 shows the average order returns of diverse traders with different proportion of switchers $(\rho)$. Thirty simulations are worn to estimate the returns for every nature of trader and five simulations are randomly selected as exposed in the outline. The same random seed is used in each simulation for the diverse types of traders. The returns of the informed traders demonstrate a small declining tendency versus $\rho$. Nevertheless, the return of the uninformed agents and switchers, illustrate a much steeper decline versus the proportion of switchers $\rho$.
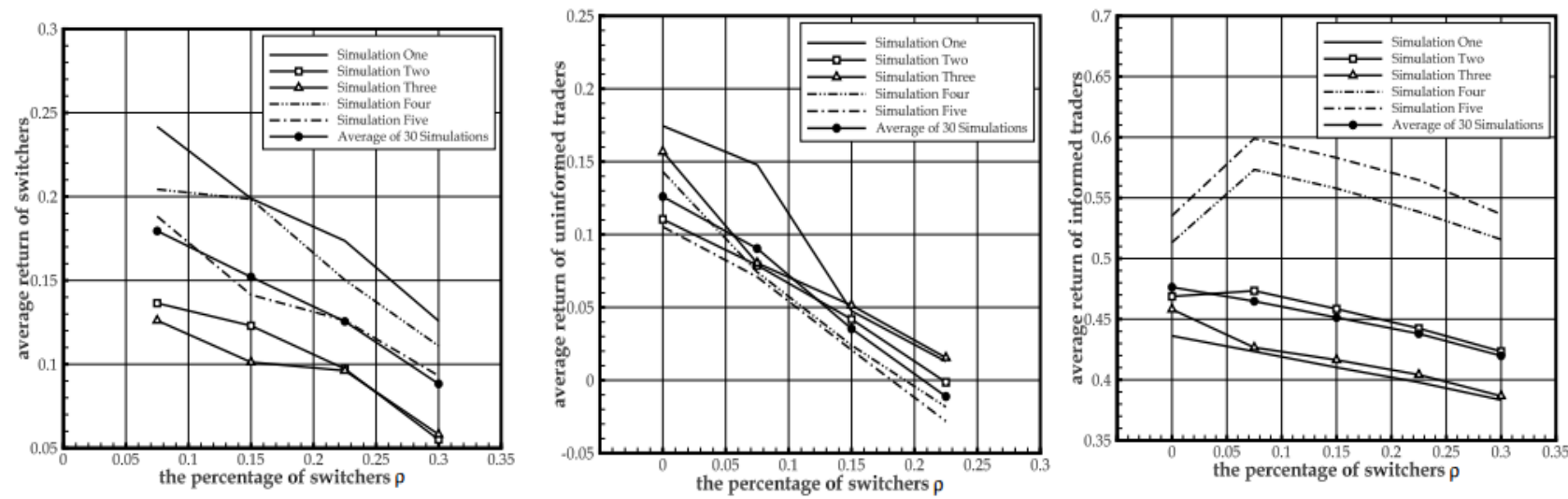

Figure 5. Different agents' returns versus $\rho$

We can see that there is no difference between the informed agents' returns while the returns in the other two types are obviously diverse under different structures of agents. Nevertheless in the case of uninformed traders the return turns down more obviously versus $\rho$. There is no difference between the returns of informed agents while the returns in the other two types are clearly different under different compositions of traders.

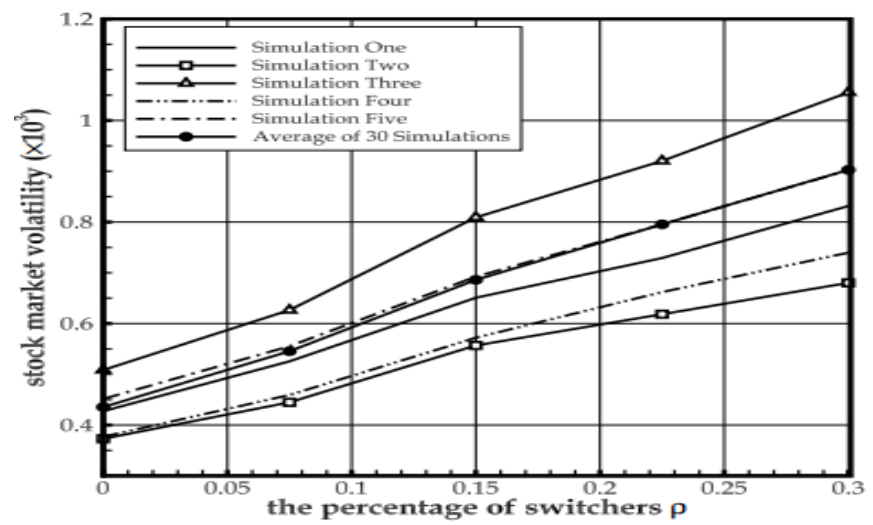

Figure 6. Volatilities of markets under different structures of agents 
Figure 6 shows market volatilities under diverse percentages of switchers. One notes that in every simulation the volatility of market is the least in the case exclusive of switchers, and we can get the similar result when building the average above 30 simulations. The primary general phenomenon we have exposed is therefore that the market with switchers fluctuates supplementary than the market with no such traders. The next one is that the superior the percentage of uninformed traders acting as switchers, $\rho$, and the larger is the volatility of the returns.

Table 4. Average market volatility under different proportion of switchers

\begin{tabular}{llllll}
\hline Percentage of switchers $\rho$ & $0 \%$ & $7 \%$ & $15 \%$ & $22 \%$ & $30 \%$ \\
\hline Average market volatility & 0.00044 & 0.00055 & 0.00070 & 0.00080 & 0.00091 \\
\hline
\end{tabular}

In conclusion, we can agree that the behavior of switchers in reality has some influences and they are a destabilizing issue on the financial market. We can elucidate such phenomena as follows: We discover that the returns of the switchers are less with better the percentage of switchers, which means that their forecasts diverge from the fundamental value more and become more inexact. Consequently the volatility is superior and they become the destabilizing reason in the financial market.

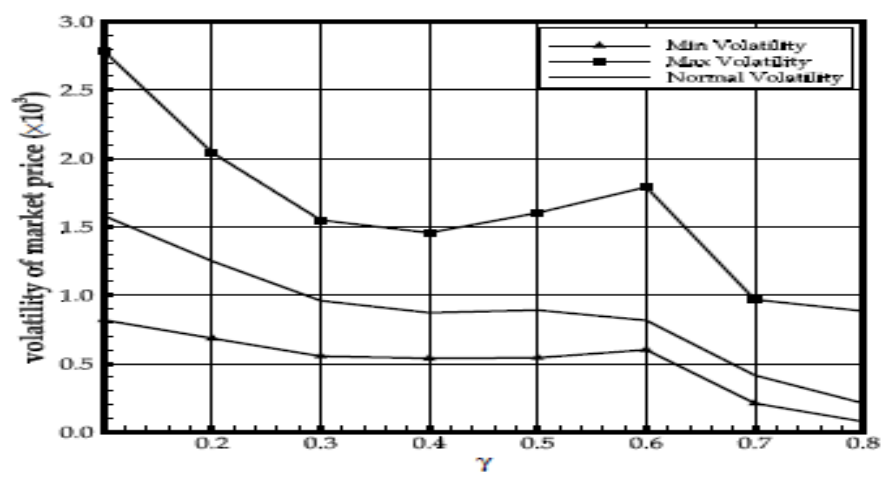

Figure 7. Average volatility under different proportions $\gamma$

We then consider for a given fixed proportion $\rho$ of switchers, how does the volatility of market depend on percentage of switchers actively buying information at a given instant of time. Figure 7 demonstrate the average volatilities as a function of $\gamma$. The data is achieved averaging more than 30 simulations using an unchanging percentage of switchers at $30 \%$. We got similar results from the other experiments with different fixed values of $\rho$. We can see that the volatility declines as the percentage of switcher's actively buying, $\gamma$, increases.

As a result we terminate that the behavior of switching have an effect on the market, and if the active switching rate is superior, the volatility will be minor. This is for the reason that more switchers switch at a given time, the transmission of information is higher and the market price is close to the fundamental value. Thus the market is more efficient and thereby more established.

\section{Conclusion}

The artificial stock markets model provides a brand new method to analyze the stock market. They are more advanced than traditional market models however. The key property is that in Artificial Stock Market environments prices should emerge internally as a result of trading interactions of the market participants characterized. The agent-based simulation gives a solution to comprehend why it is not converging in some instances, then how much can be discerned about the out of equilibrium formation, and learning behavior of the financial market.

This study presents a computer simulation of the stock market based on the input variables which include a single financial asset, tick size, transaction cost and type of investors in a continuous double auction market. The preliminary results of this paper show that the artificial market approach is effective for understanding real financial markets. Based on the heterogeneous beliefs in artificial, we can make a support system for decision making in terms 
of market dynamics. Secondly we have analyzed the effect of switching on the returns of the traders as well as on the volatilities of market under diverse circumstances. We have interpreted our result that strategy switching by different participants would have a significant impact on market stability.

Our results help to confirm switch strategies as well as its impacts on the persistent deviations of the fundamental value, which are significant results in agent model hypothesis. We examine the interaction of diverse traders' behavior and their influence on market volatility by means of data that describe trading of all traders types in the financial market. Finally, we terminate our argument with certain potential additions of our study. The model in this paper can be developed further to model more complicated learning and adaptive behavior of traders. More realistically, they may also learn from other market information such as the types of the last trading, trading volume, the depth and shape of the order book.

\section{References}

Anufriev, M., Arifovich, J., Ledyard, J., \& Panchenko, V. (2013). Efficiency of continuous double auctions under individual evolutionary learning with full or limited information. Journal of Evolutionary Economics. http://dx.doi.org/10.1007/s00191-011-0230-8

Barberis, C., \& Thaler, H. (2003). A survey of Behavioral Finance. Handbook of the Economics of Finance, 1, 1053-1128. http://dx.doi.org/10.1016/S1574-0102(03)01027-6

Boswijk, P. Hommes, C., \& Manzan, S. (2007). Behavioral heterogeneity in stock price. Journal of Economic Dynamics and Control, 31, 1938-1970. http://dx.doi.org/10.1016/j.jedc.2007.01.001

Brock, W., \& Hommes, C. (1998). Heterogeneous Beliefs and Routes to Chaos in a Simple Asset Pricing Model. Journal of Economic Dynamics and Control, 22, 1235-1274. http://dx.doi.org/10.1016/S0165-1889(98)00011-6

Chakraborti, A., \& Tokeb, M. (2009). Empirical facts and agent-based models. General Finance.

Chiarella, C. (1992). The dynamics of speculative behavior. Annals of Operations Research, 37, 101-123. http://dx.doi.org/10.1007/BF02071051

Chiarella, C., \& He, Z. (2003). Heterogeneous Beliefs, Risk and Learning in a Simple Asset Pricing Model with a Market Maker. Macroeconomic Dynamics, (7), 503-536.

Chiarella, C., Iori, G., \& Perell, J. (2009). The impact of heterogeneous trading rules on the limit order book and order flows. Journal of Economic Dynamics and Control, 33, 525-537. http://dx.doi.org/10.1016/j.jedc.2008.08.001

Cont, R. (2001). Empirical Properties of Asset Returns: Stylized Facts and Statistical Issues. Quantitative Finance, 1, 223-236. http://dx.doi.org/10.1080/713665670

Day, R., \& Huang, W. (1990). Bulls, bears and market sheep. Journal of Economic Behavior and Organization, 14, 299-329. http://dx.doi.org/10.1016/0167-2681(90)90061-H

De Grauwe, P., Dewachter, H., \& Embrechts, M. (1993). Exchange Rate Theories. Chaotic Models of the Foreign Exchange Market. Blackwell, Oxford.

Engel, F. (1982). Autoregressive Conditional Heteroscedasticity with Estimates of the Variance of United Kingdom Inflation. Econometrica, 50(4), 987-1007. http://dx.doi.org/10.2307/1912773

Farmer, J., \& Joshi, S. (2002). The Price Dynamics of Common Trading Strategies. Journal of Economic Behavior and Organization, 49, 149-171. http://dx.doi.org/10.1016/S0167-2681(02)00065-3

Gallegati, M., Palestrini, A., \& Rosser, J. (2011). The period of financial distress in speculative markets: interacting heterogeneous agents and financial constraints. Macroeconomic Dynamics, 15, 60-79. http://dx.doi.org/10.1017/S1365100509090531

Gaunersdorfer, A., Hommes, C., \& Wagener, F. (2008). Bifurcation routes to volatility clustering under revolutionary learning. Journal of Economic Behavioral and Organization, 67, 27-47. http://dx.doi.org/10.1016/j.jebo.2007.07.004

Goettler, R., Parlour, A., \& Rajan, U. (2009). Informed traders and limit order markets. Journal of Financial Economics, 93(1), 67-87. http://dx.doi.org/10.1016/j.jfineco.2008.08.002

Harrison B., Lupu R., \& Lupu I. (2010). Statistical Properties of the CEE Stock Market Dynamics: A Panel Data Analysis. The Romanian Economic Journal, 37, 41-54. 
He, X., \& Li, Y. (2008). Power-law behavior, heterogeneity, and trend chasing. Journal of Economic Dynamics and Control, 31, 3396-3426. http://dx.doi.org/10.1016/j.jedc.2006.11.008

Hommes, C. (2006). Handbook of Computational Economics: Agent-based Computational Economics, Vol. 2. Amsterdam, North-Holland, pp. 1107-1186.

Huang, W., Zheng, H., \& Chia, W. (2010). Financial crises and interacting heterogeneous agents. Journal of Economic Dynamics and Control, 34, 1105-1122. http://dx.doi.org/10.1016/j.jedc.2010.01.013

Huang, W., Zheng, H., \& Chia, W. (2012). Asymmetric returns, gradual bubbles and sudden crashes. European Journal of Finance, forthcoming.

Jiri, K., \& Jozef, B. (2013). Behavioral Breaks in the Heterogeneous Agent Model: The Impact of Herding, Overconfidence, and Market Sentiment. Statistical Mechanics and Its Applications, 392(23), 5920-5938. http://dx.doi.org/10.1016/j.physa.2013.07.050

Kirman, A. (1993). Ants, rationality, and recruitment. Quarterly Journal of Economics, 108, 137-156. http://dx.doi.org/10.2307/2118498

LeBaron, B. (2006). Handbook of Computational Economics: Agent-based Computational Economics, Vol. 2. Amsterdam, North-Holland, pp. 1187-1233.

LeBaron, B., Arthur, B., \& Palmer, R. (1999). Time Series Properties of an Artificial Stock Market. Journal of Economic Dynamics and Control, 23, 1487-1516. http://dx.doi.org/10.1016/S0165-1889(98)00081-5

Lux, T. (1995). Herd behavior, bubbles and crashes. Economic Journal, 105, 881-896. http://dx.doi.org/10.2307/2235156

Lux, T. (2009). Handbook of Financial Markets: Dynamics and Evolution. Amsterdam, North-Holland, pp. 161-216. http://dx.doi.org/10.1016/B978-012374258-2.50007-5

Lux, T., \& Marchesi, M. (1998). Scaling and Criticality in a Stochastic Multi-Agent Model of a Minancial market. Nature, 397, 498-500. http://dx.doi.org/10.1038/17290

Lux, T., \& Marchesi, M. (2000). Volatility Clustering in Financial Markets: A Micro simulation of Financial Agents. International Journal of Theoretical and Applied Finance, 675-702. http://dx.doi.org/10.1142/S0219024900000826

Lux, T., \& Westerhoff, F. (2009). Economics Crisis. Nature Phys, 5, 2-3. http://dx.doi.org/10.1038/nphys1163

Manahov, V., \& Robert, H. (2013). Herd Behavior Experimental Testing in Laboratory Artificial Stock Market Settings: Behavioral Foundations of Stylized Facts of Financial Returns. Physica A: Statistical Mechanics and Its Applications, 392(19), 4351-4372. http://dx.doi.org/10.1016/j.physa.2013.05.029

Rosu, I. (2010). Liquidity and information in order driven markets, Working paper, SSRN.

Tesfatsion, L., \& Judd, K. (eds.) (2006). Handbook of Computational Economics. North-Holland, Amsterdam.

Tversky, A., \& Kahneman, D. (1974). Judgment Under-Uncertainty: Heuristics and Biases. Science, 1124-1131. http://dx.doi.org/10.1126/science.185.4157.1124

Wei, J. Zhang, W., He, Z., \& Zhang, Y. (2013). Learning and information dissemination in limit order markets. http://dx.doi.org/10.2139/ssrn.2276350

Westerhoff, F. (2009). Handbook of Research on Complexity. Edward Elgar, Cheltenham, pp. 287-325.

Yamamoto, R., \& Hirata, H. (2013). Strategy switching in the Japanese stock market. Journal of Economic Dynamics and Control, 37, 2010-2022. http://dx.doi.org/10.1016/j.jedc.2013.05.006 